\title{
Leaders
}

\section{Girls and fitness: fact and fiction}

"Almost from the age when girls are old enough for exercise testing, a progressive decline occurs in weight-relative maximal $\mathrm{O}_{2}$ uptake that persists throughout the childhood and teen years" ( $\mathrm{p} \mathrm{80).}{ }^{1}$

This quote from a recent textbook summarises what has been the accepted interpretation of developmental changes in girls' aerobic fitness since data were published from the first laboratory studies to include young females. ${ }^{2}$ Thus the popular perception that the aerobic fitness of girls, particularly teenage girls, is a problem would appear to have at least some basis in scientific fact. But is this really the case? Do girls' fitness levels really give cause for concern, or have we simply been misled by the use of an inappropriate method of accounting for changes in body size during growth?

Fitness has many components but in the context of aerobic fitness the highest oxygen consumption attained during progressive exercise to exhaustion-peak (or maximal) $\mathrm{V}_{2}$ - is accepted as the gold standard criterion ${ }^{3}$ and has been extensively documented in girls aged 8-18 years. As peak $\dot{\mathrm{V}}_{2}(\mathrm{l} / \mathrm{min})$ correlates strongly with body size, values are traditionally expressed as a ratio to body massthat is, as $\mathrm{ml} / \mathrm{kg} / \mathrm{min}$. Expressed thus, girls' peak $\dot{\mathrm{V}}_{2}$ falls from around 45 to $35 \mathrm{ml} / \mathrm{kg} / \mathrm{min}$ between the ages of 8 and 16 years, with the decline usually attributed to the effect of maturational increases in body fat. However, when the physiological and body compositional changes that take place during maturation are considered as a whole, it is perhaps strange that this pattern of change has been accepted, almost without question, for over 40 years. Girls do accumulate body fat, increasing from about $18 \%$ before puberty to $25 \%$ after adolescence, but they also experience an adolescent growth spurt in muscle mass relative to total body mass, and haemoglobin increases from around 128 $\mathrm{g} / \mathrm{l}$ before puberty to peak at $138 \mathrm{~g} / 1$ in adolescence. This potential for improved oxygen delivery and utilisation seems somewhat at odds with the picture of a progressive decline in oxygen consumption observed when values are expressed in simple mass relative terms.

In a series of recent studies, we have shown that simple mass ratios inadequately remove body size effects from young peoples' exercise performance measures. In particular, this work suggests that the decline in girls' fitness has its basis in statistical artefact rather than physiological explanation. When used to correct exercise performance measures, simple per body mass ratios tend to "overscale" - that is, rather than removing the effect of mass from peak $\dot{\mathrm{V}}_{2}$, mass relative values retain a negative correlation with body mass. This has the effect of artificially advantaging light and penalising heavier individuals. ${ }^{4}$ As body mass increases during normal growth and maturation, children are predestined to become less fit simply as a function of the statistical limitations of ratio scaling. When body mass is controlled using more appropriate allometric scaling techniques, a remarkably different picture emerges. In contrast with the accepted decline, girls' fitness can be seen to increase significantly between prepuberty and circumpuberty, with these levels of fitness then sustained into young adulthood. ${ }^{5}$ Similarly, in contrast with the traditional assumption that increasing biological age has a negative impact on aerobic fitness, we have shown in girls of the same chronological age that those advanced in biological age have significantly greater, not lower, peak aerobic fitness relative to body mass than their more immature peers when body mass is appropriately controlled for. ${ }^{6}$ Data from our longitudinal study of 11-13 year olds has confirmed separate age and maturity related increments in peak $\dot{\mathrm{V}}_{2}$ which are independent of body size and composition effects. ${ }^{7}$ This alternative interpretation of the growth of peak aerobic fitness in girls provided by more appropriate scaling methods is also entirely consistent with the underlying physiological changes alluded to earlier.

This alternative interpretation of girls' fitness is without question more positive, but, even when scaled appropriately, girls' peak $\dot{\mathrm{V}}_{2}$ remains considerably lower than that of boys. During adolescence, sex differences may be explained by boys' higher haemoglobin levels, greater muscle mass, and lower body fat, but even during prepuberty when such differences are absent peak aerobic fitness in girls is some $16 \%$ lower than in boys. ${ }^{8}$ Does this suggest that girls' aerobic fitness is in some way suboptimal, perhaps reflective of an inactive lifestyle?

There is considerable evidence confirming that girls are substantially less active than boys and that the time spent in moderate and vigorous physical activity declines throughout childhood and adolescence. For example, whereas more than $85 \%$ of five year old girls accumulate 30 minutes of moderate activity daily, by the age of 14 this figure has fallen to below $20 \% .{ }^{9}$ Sustained physical activity is rare, with $45 \%$ of teenage girls not achieving a single 10 minute period of brisk walking during three days of monitoring. ${ }^{4}$ Data from our longitudinal study have confirmed age related declines in the percentage time spent in moderate and vigorous physical activity and shown an additional negative effect of late maturity. However, these low levels of activity do not appear to influence girls' peak aerobic fitness, as we have consistently failed to identify significant relations between activity measures and peak $\dot{\mathrm{V}}_{2}$ in prepubertal and pubertal girls. ${ }^{4}$

Compelling evidence that peak fitness levels are not suboptimal derives from studies that have involved girls in structured exercise training programmes. In 10 year olds, peak $\dot{\mathrm{V}}_{2}$ did not increase after eight weeks of three times weekly aerobic training, ${ }^{10}$ and peak fitness was similarly unaffected by a 12 week training programme in 13 to 14 year old girls (K Stoedefalke, N Armstrong and BJ Kirby, unpublished work). Even when training continued for a further eight weeks, peak $\dot{\mathrm{V}}_{2}$ remained unchanged in the teenagers.

To conclude, the use of traditional ratio scaling provides a misleading picture of the growth and development of girls' peak aerobic fitness. Recent work has consistently shown that peak $\dot{\mathrm{V}}_{2}$ does not decline but continues to increase, at least into puberty, despite a sedentary lifestyle. The absence of change in peak $\dot{\mathrm{V}}_{2}$ with training further suggests that girls' fitness levels are not suboptimal. These findings are very positive but present no grounds for complacency. The inactive lifestyle of the average girl remains a serious concern, particularly given the importance of activity during adolescence for optimising skeletal health, and it is towards raising their activity levels that our efforts should be directed.

JOANNE R WELSMAN Children's Health and Exercise Research Centre, University of Exeter, Exeter EX1 2LU, United Kingdom 
1 Rowland TW. Developmental exercise physiology. Champaign, IL: Human Kinetics, 1996.

2 Åstrand PO. Experimental studies of physical working capacity in in relation to sex and age. Copenhagen: Munksgaard, 1952.

3 Armstrong N, Welsman J. Assessment and interpretation of aerobic fitness in children and adolescents. Exerc Sport Sci Rev 1994;22:435-76.

4 Armstrong N, Welsman J. Young people and physical activity. Oxford: Oxford University Press, 1997:1-369.

5 Welsman J, Armstrong N, Kirby BJ, et al. Scaling peak oxygen uptake for differences in body size. Med Sci Sports Exerc 1996;28:259-65.
6 Armstrong N, Welsman JR, Kirby BJ. Peak $\dot{\mathrm{V}}_{2}$ and maturation in 12-yr Alds. Med Sci Sports Exerc 1998:30:165-9.

7 Armstrong N, Welsman JR, Nevill AM, et al. Modeling growth and maturation changes in peak oxygen uptake in 11-13-year olds. F Appl Physiol in press.

8 Armstrong N, McManus AM, Welsman JR, et al. Aerobic fitness of pre-pubescent children. Ann Hum Biol 1995;22:427-41.

Armstrong, N. Young people's physical activity patterns as assessed by heart rate monitoring. I Sports Sci 1998;16:S9-16.

10 Welsman JR, Armstrong N, Withers S. Responses of young girls to two modes of aerobic training. Br f Sports Med 1997;31:139-42.

\section{Role of sport and exercise medicine in the NHS}

Given the overwhelming evidence identifying the benefits associated with regular participation in a variety of forms of physical activity, ${ }^{1}$ it is hardly surprising that it occupies a significant portion of the government's policy and associated strategy on health. However, one must keep the evidence base for this in perspective, as, although there is significant research on the positive outcomes of physical activity, there is surprisingly little on the "effectiveness" of physical activity promotion schemes. It is also clear from the available research evidence that people's perception of an increase in physical activity is generally based on an often transient flirtation with exercise and sport rather than as activities performed as part of daily life. $^{2}$

It could be further argued therefore that the successful promotion of a sustainable and more physically active lifestyle for all will need careful consideration following the publication of the government's "Sport Strategy" document (Saving lives: our healthier nation). ${ }^{3}$ The Government may express the desire "to help support the enthusiasm for physical activity and for better health" through the sports strategy in order to "promote greater scope for participation in sport and physical activity for all", ${ }^{3}$ but this seems too simplistic a strategy. Not only are the terms sport and physical activity used synonymously, but the assertions fail to acknowledge, yet alone explore, the costs of provision, the inevitable political conflicts, the cost in health care associated with participation, and even the fact that most of the population fail to take an active part in any kind of sport.

"Saving lives" advocates specific sports programmes to encourage activity among people with such conditions as stress, obesity, and diabetes, but this approach fails to acknowledge the evidence that suggests that many of these groups find sport unappealing because of a perception that to play sport you have to be "fit" and "skilful".4 ${ }^{5}$ These people will often be turned off sport at a very young age. The difficulty with "sport" is that it cannot always be appropriately regulated to minimise injury or to provide the most appropriate sustained intensity of physical activity. Other physical activities may do this more successfully, allowing for guidelines that differentiate between not only the level of activity that population studies have suggested is protective, but the level and type of activity that is sustainable and can reasonably be expected of most people. $^{6}$

Clearly primary care is the key arena in which the Government sees the health promotion message being delivered. However, within this arena there exist a number of tensions that may inhibit its success. Even acknowledging the many very good general practitioner projects that exist at a time of scarce primary resources and within a climate of evidence based practice, are all general practitioners necessarily positioned to be the most sympa- thetic source of advice and support for those seeking to take part or already involved in physical activity? Regardless of whether they have been involved in physical activity promotion schemes for either prevention or treatment, the attitude of many general practitioners has inevitably been influenced by the demands on their time and budget. It will be essential for the future that primary care teams embrace the government policy on the promotion of physical activity with rather more conviction. While making this statement, one must also remember that the promotion and sustainability of appropriate levels of physical activity in the population is not the sole responsibility of the primary care sector. Yes, it plays a significant role, but it has to be in conjunction with other agents/agencies, to which it is sympathetic and from which it receives sympathy.

In the future therefore it is clear that the NHS must facilitate greater initial training for general practitioners in relation to the benefits of physical activity and more importantly give clearer guidance as to the most appropriate sustainable forms of physical activity, including sport. In addition there has to be substantial coordination of initiatives between agents such as general practitioners, health promotion units, community, and national governing bodies of sport. Such collaboration should not only take the form of the provision and dissemination of information and good practice during initial training and continual professional development, but mutual research opportunities and pooling of expertise will be essential to move the evidence base significantly beyond the predominantly physiological outcomes trumpeted in the past, to incorporate other feel good factors. In order to achieve all of this, more time and specific funding need to be made available, and crucially, this whole programme must be collaboratively developed and coordinated by designated individuals/units who are informed and trained to facilitate provision at a local, regional, and national level.

KENNETH CALMAN MICHAEL WARING PETER WARBURTON

School of Education, University of Durham, United Kingdom

1 Bouchard C, Shephard RJ, Stephens T (eds). Physical activity, fitness, and health: international proceedings and consensus statement. Champaign, IL: Human Kinetics, 1994.

2 Bridgwood A, Rainford L, Walker A. All change? The health education monitoring survey one year on. London: HMSO, 1998.

3 Secretary of State for Health. Saving lives: our healthier nation. London: HMSO, 1999.

4 Kremer J, Trew K, Ogle S. Young people's involvement in sport. London: Routledge, 1997

5 Health Education Authority. Young people and physical activity: a literature review. London, Health Education Authority, 1997.

6 Riddoch C, Puig-Ribera A, Cooper A. Effectiveness of physical activity promoRiddoch C, Puig-Ribera A, Cooper A. Effectiveness of physical activity promo-
tion schemes in primary care: a review. London: Health Education Authority, 


\section{The genetics of physical fitness}

It is clear to most schoolchildren that sporting prowess is powerfully influenced by the genes we carry. In playground races, some children would always seem to win, and others to come last. Ranking orders remained very much the same no matter how hard we tried. Only in later life was the impact of dedicated training, or of idling on street corners, seen. Further, the offspring of "athletic" parents seemed to have the best chance. As we grew older, we noticed that some nationalities excelled in particular events. Our instincts as children were not wrong, of course. Modern scientific investigations have confirmed the significant heritability of measures of reaction time, flexibility, and even balance. Over three quarters of the variance in explosive strength in prepubertal females may be explained by genetic factors.

There are many potential ways in which such genetic factors may exert their effects. Human body morphology and composition are influenced by genetic variables. Up to $80 \%$ of the individual variance in femoral neck bone mineral density and lean muscle mass, ${ }^{2}$ and $85 \%$ of the covariance in arm cross sectional area in twin studies may be genetically determined. ${ }^{3}$ Pretraining aspects of muscle function such as arm flexor strength are influenced by inheritance to a similar degree, ${ }^{3}$ while up to $50 \%$ of the variability in $\mathrm{VO}_{2} \mathrm{MAX}$ may be due to genetic influences. ${ }^{4}$ Against this background, the wish to participate in physical activity may be partly dictated by our genetic constitution. In a study of 3344 men aged 31-51 years, participation in moderate or intense regular exercise, the use of stairs rather than lifts, and habitual walks after meals were all more strongly correlated in monozygotic than dizygotic twins, with significant heritability suggested for the choice to walk rather than drive, park away from destinations in order to walk more, or to jog or run $>10$ miles a week. ${ }^{5}$ The training response to such participation is also influenced by genetic variation between individuals, as has been shown for the effect of training on maximum voluntary force of muscle contraction and isometric strength. ${ }^{6}$

The number of genes that may influence such variability is likely to be enormous. One could envisage genes affecting contractile proteins, calcium and ion flux, tissue elasticity, lung structure and function, respiratory drive, buffering capacity, muscle growth, food absorption, metabolic substrate-for example, glucose or non-esterified fatty acid-storage, release and uptake ... The list is almost endless. The key question therefore has to be answered: why bother to look? There may be many reasons, but the poorest of all has to be mere scientific curiosity. Exercise has profound beneficial effects on human health. Mortality and morbidity from coronary heart disease are dramatically reduced by engagement in regular exercise. Other disease risks may be reduced through secondary effects on, for instance, reduced body mass. If we could elucidate quite how such benefits accrue, then it may be possible to intervene pharmacologically in a variety of disease states that are currently hard to treat.

Angiotensin I converting enzyme (ACE) degrades vasodilator kinins and generates the vasopressor growth factor angiotensin II. A variant of the ACE gene has been identified in which the absence (deletion or D allele) rather than the presence (insertion or I allele) of a $287 \mathrm{bp}$ fragment is associated with higher tissue ACE levels. We have shown that the I allele is associated with an 11-fold greater endurance response to training in loaded repetitive biceps flexion. ${ }^{7}$ It is also associated with improved performance at high altitude, ${ }^{7}$ and a relatively anabolic response to mixed exercise training. ${ }^{8}$ The $\mathrm{D}$ allele, on the other hand, is associated with greater cardiac growth with such training. ${ }^{9}$ So what? Well, drugs that lower ACE levels (ACE inhibitors) are associated with dramatic improvements in survival in those with diseases such as heart failure after heart attacks. ${ }^{10}$ Studies of the ACE gene and exercise start to give clues as to why. Could it be that lower tissue ACE levels are associated with an enhanced metabolic efficiency, for instance? More extensive studies are likely to elucidate the answer, and may refine pharmacotherapy still further.

We must be cautious, however, that such research is not misused. The advances in related technologies in the coming years will rapidly identify a wealth of loci associated with performance. We may soon be able to read a "DNA profile" for performance related genes in a trice on any individual. There are those who would misuse such information. Nonetheless, genetic research into human performance should continue, but with thought and due care. We must ensure that new discoveries are not misused (for instance, in attempts to select athletes for training). We must also take care that our new found knowledge does not lead to a diminution of humanity: we are more than mere code strips. And finally, we must remember that exercise is meant to be fun. It serves a social and psychological purpose, as well as a physical one. Surely, it is better to try and fail, than to be told from the outset that we stand no chance? We must encourage faith in the ability to overcome through determination and dedication, rather than dispensing excuses to concede and condemn.

HUGH MONTGOMERY DAVID WOODS

UCL Centre for Cardiovascular Genetics, Rayne Institute, London WC1E 67 F

1 Maes HH, Beunen GP, Vlietinck RF, et al. Inheritance of physical fitness in 10-year-old twins and their parents. Med Sci Sports Exerc 1996;28:1479-91. Seeman E, Hopper JL, Young NR, et al. Do genetic factors explain associations between muscle strength, lean mass, and bone density? A twin study. Am F Physiol. 1996;270:E320-7.

3 Thomis MA, Beunen GP, Van Leemputte M, et al. Inheritance of static and dynamic arm strength and some of its determinants. Acta Physiol Scand 1998;163:59-71.

4 Bouchard C, Daw EW, Rice T, et al. Familial resemblance for VO2max in the sedentary state: the HERITAGE family study. Med Sci Sports Exerc 1998:30:252-8.

5 Lauderdale DS, Fabsitz R, Meyer JM, et al. Familial determinants of moderate and intense physical activity: a twin study. Med Sci Sports Exerc 1997; 29:1062-8.

6 Thomis MA, Beunen GP, Maes HH, et al. Strength training: importance of genetic factors. Med Sci Sports Exerc 1998;30:724-31.

7 Montgomery HE, Marshall RM, Hemingway H, et al. Human gene for physical performance. Nature 1998;393:221-2

8 Montgomery H, Clarkson P, Barnard M, et al. Angiotensin-convertingenzyme gene insertion/deletion polymorphism and response to physical training. Lancet 1999;353:541-5.

9 Montgomery HE, Clarkson P, Dollery CM, et al. Association of angiotensin-converting enzyme gene I/D polymorphism with change in left ventricular mass in response to physical training. Circulation 1997;96:7417.

10 AIRE Study Investigators. Effect of ramipril on mortality and morbidity of survivors of acute myocardial infarction with clinical evidence of heart failure. Lancet 1993;342:821-8. 


\section{Acute mountain sickness-the "poison of the pass"}

Few sights are more breathtaking and inspirational than a mountain peak, yet behind the innocence and majesty of one of nature's wonders lies a sleeping evil, acute mountain sickness (AMS). The constellation of symptoms that characterise AMS are a frequent cause of morbidity and occasional mortality and affect $25 \%$ of travellers sojourning to altitudes between 1900 and $3000 \mathrm{~m} .{ }^{1}$ Joseph de Acosta, a Jesuit priest, presented the first classical account of the physical symptoms associated with mountain sickness in 1604 during a climbing expedition to Peru" : "........I was suddenly surprised with so mortall and strange a pang, that I was ready to fall from the top to the ground............ w was surprised with such pangs of straining and casting as I thought to cast up my heart too: for having cast up meate, fleugme and choller both yellow and greene, in the end I cast up blood with the straining of my stomach. To conclude, if this had continued I should undoubtedly have died."

These early accounts of "ladrak", a Tibetan term which literally translates to "poison of the pass", are not far removed from complaints of frontal headaches, lassitude, insomnia, and peripheral oedema experienced by modern day AMS sufferers, symptoms that usually resolve within four to five days but if left untreated may progress to the life threatening malignant forms of high altitude pulmonary and cerebral oedema. Although the precise mechanisms of AMS and its related sequelae remain elusive, a low hypoxic ventilatory drive, water retention, and increased vascular permeability are recognised as the most important pathophysiological factors. ${ }^{3}$ Arterial oxygenation decreases as a function of the hypobaria at terrestrial altitude, and thus tissue hypoxia is considered a "trigger" for these changes.

We recently participated in a medical expedition to the world's third highest mountain, Mt Kanchenjunga $\left(\mathrm{K}_{3}\right)$, which was designed to increase knowledge and awareness of altitude related illnesses. Our aims were to determine the physiological implications of AMS and establish constitutional risk factors that may be important in its pathogenesis. Specific attention focused on metabolic events that could result in potential changes in vascular permeability and the subsequent formation of oedema.

Our preliminary findings raise questions about the structural integrity of muscle or cardiac cell membranes at high altitude and its role in the pathogenesis of AMS. The source of membrane damage, which may be more pronounced in those subjects presenting with AMS, may be linked to an increased activity of oxygen free radicals. Changes in vascular function at high altitude as a consequence of increased free radical mediated oxidative stress may also prove a topic worthy of investigation in the future. Whether increased susceptibility to membrane damage as the result of a deficient antioxidant defence system is the cause or consequence of AMS and related sequelae remains to be elucidated.

Physical symptoms associated with upper respiratory and gastrointestinal tract illnesses are ubiquitous among mountaineers who ascend to high altitude. Although these illnesses may present without an infectious aetiology, the role of some potentially immunoprotective amino acids needs to be investigated. For example, previous accounts of a decrease in plasma glutamine at altitude, ${ }^{4}$ a conditionally essential amino acid required for optimal lymphocyte proliferation and macrophage phagocytosis, ${ }^{5}$ may increase a mountaineer's susceptibility to opportunistic infections. The subsequent release of vasoactive inflammatory mediators may be implicated in the pathogenesis of localised pulmonary oedema which would exacerbate arterial hypoxaemia, physiological phenomena that could account for at least some of the debilitating symptoms ascribed to AMS. We are currently conducting a double blind placebo controlled glutamine supplementation study in the Himalayas to explore further the potential link between infection and susceptibility to AMS.

Cachexia, which is an almost inevitable consequence of high altitude mountaineering, may also be related to possible changes in immunoreactivity, and, although previously considered a maladaptive response, may well prove to be of functional significance. The major source of nitrogen for glutamine formation are the branched chain amino acids (BCAAs), their metabolism being largely confined to skeletal muscle. ${ }^{6} \mathrm{~A}$ decrease in serum BCAA concentration previously observed at high altitude ${ }^{7}$ may signal for the endogenous catabolism of skeletal muscle to provide a constant supply of BCAAs and thus glutamine, the latter amino acid being required as a substrate for lymphocytes and macrophages during more active immunosurveillance.

The use of AMS prophylactics such as acetazolamide, which functions as a respiratory stimulant by inhibiting carbonic anhydrase, has become increasingly popular among mountaineers. Alternative strategies that incorporate nutritional supplementation with amino acids and antioxidants at high altitude may also prove useful in the battle against AMS. Understanding, preventing, and treating altitude illness remains a constant challenge for the mountain physiologist.

DAMIAN M BAILEY

University of Glamorgan

1 Honigman B, Theis MK, Koziol-McLain J, et al. Acute mountain sickness in a general toursist population at moderate altitudes. Ann Intern Med 1993;118:587-92.

2 Jarcho S. Mountain sickness as described by Fray Joseph de Acosta, 1589. Am $\mathcal{F}$ Cardiol 1958;2:246-7.

Scott Johnson T, Rock PB. Current concepts: acute mountain sickness. $N$ Engl f Med 1988;319:841-5.

4 Bailey DM Davies B, Romer L, et al. Implications of moderate altitude training for sea-level endurance in elite distance runners. Eur $\mathcal{F}$ Appl Physiol 1997;78:360-8.

5 Ardawi, MSM, Newsholme EA. Metabolism in lymphocytes and its importance to the immune system. Essays Biochem 1985;21:1-44.

6 Newsholme, EA, Newsholme P, Curi R, et al. A role for muscle in the immune system and its importance in surgery, trauma, sepsis and burns. Nutrition 1998;4:261-8.

7 Bigard AX, Satabin P, Lavier P, et al. Effect of protein supplementation during prolonged exercise at moderate altitude on performance and plasma amino acid pattern. Eur F Appl Physiol 1993;66:5-10. 


\section{Can exercise induced muscle damage be avoided?}

All athletes have experienced the discomfort and debilitating effects of exercise induced muscle damage. The symptoms are most commonly experienced at the beginning of the season when intense training is re-introduced after a period of relative inactivity. A plethora of scientific data is available describing exercise conditions resulting in exercise induced muscle damage. It is well accepted that damage occurs with unfamiliar exercise, primarily involving eccentric contractions. For example, downhill running places a large eccentric stress on the quadriceps muscle group and commonly results in muscle damage. ${ }^{1}$ However, muscles that have been preconditioned with eccentric contractions are protected against damage from subsequent bouts of eccentric exercise. This is known as the repeated bout effect and has been shown with various forms of exercise in both humans and animal models. ${ }^{2}$ Despite the number of studies describing muscle damage and its various clinical symptoms, few studies have identified intrinsic causative factors or suitable interventions for limiting the symptoms. Clinically, it is important to first identify people at risk of developing more severe symptoms and secondly to develop interventions that might limit those symptoms. Three recent experimental studies provide clinically relevant information for athletes and practitioners. ${ }^{356}$

Controlled experimental studies have shown high variation in symptoms between subjects after a bout of unfamiliar eccentric exercise. These data indicate that some people are more susceptible to damage than others, but it is not clear why. McHugh et $a \beta^{3}$ recently showed that musculoskeletal flexibility is an important factor affecting the severity of symptoms after eccentric exercise. Flexibility was quantified according to a measure of passive muscle stiffness, and subjects were categorised as having "stiff", "normal", or "compliant" muscles. After a bout of eccentric exercise, subjects with stiff muscles experienced significantly greater strength loss, pain, muscle tenderness, and elevation of plasma creatine kinase activity than those with compliant muscles. Greater apparent muscle damage was attributed to the inability of the tendon and aponeurosis of stiffer muscles to absorb the lengthening imposed by the eccentric contractions.

Warm up and stretching are known to acutely reduce muscle stiffness. ${ }^{4}$ As stiffness seems to predispose muscle to damage, it follows that appropriate warm up before exercise may reduce the severity of subsequent exercise induced muscle damage. Nosaka and Clarkson ${ }^{5}$ recently showed that warm up does, in fact, reduce subsequent symptoms of muscle damage. Eccentric contractions of the elbow flexors preceded by a warm up resulted in significantly less strength loss and elevation of plasma creatine kinase activity compared with eccentric contractions without prior warm up. The protective effect was attributed to decreased passive muscle stiffness, although actual stiffness measurements were not made.

Besides the possible role of warm up in limiting the symptoms of muscle damage, it is clear that precondition- ing the muscle with eccentric contractions will provide a protective effect (repeated bout effect). Recent data suggest that it may not be necessary to damage the muscle with the initial bout in order to provide a protective effect. ${ }^{6}$ Brown et $a l^{6}$ showed that as few as 10 maximal eccentric contractions of the knee extensors were sufficient to reduce symptoms appreciably after a subsequent bout of 50 maximal contractions, performed three weeks later. There was a clear repeated bout effect despite the fact that 10 contractions did not result in appreciable muscle damage. These data indicate that preconditioning muscles with a few maximal eccentric contractions can considerably reduce symptoms after a subsequent, more intense, bout of eccentric exercise. The key elements for the repeated bout effect are that $(a)$ the preconditioning contractions are eccentric; (b) high intensity contractions are performed; (c) the preconditioning contractions affect the same muscle groups that will be working eccentrically in the repeated bout.

In reality, all dynamic sports activities will involve a large component of high intensity eccentric contractions, whether the activity is in a game or a practice. Athletes typically experience considerable symptoms of muscle damage when returning to these activities after a prolonged lay off owing to injury or after the off season. However, the severity of these symptoms may be reduced by (a) maintaining good flexibility, especially of the principal muscle groups involved in the given sport; $(b)$ preconditioning the principal muscle groups with a few high intensity eccentric contractions one to two weeks before the return to full activities; $(c)$ performing specific warm up exercises for the principal muscle groups immediately before the first few training sessions or games. Increasing the athlete's awareness of the cause of the symptoms will increase compliance with any intervention directed at limiting muscle damage. This is especially important in sports that do not place a large emphasis on warm up or flexibility.

Nicholas Institute of Sports Medicine and Athletic Trauma, Lenox Hill Hospital, New York, NY 10021, USA

1 Eston RG, Mickleborough J, Baltzopoulos V. Eccentric activation and muscle damage: biomechanical and physiological considerations during downhill running. Br f Sports Med 1995;29:89-94

2 McHugh MP, Connolly DAJ, Eston RG, et al. Exercise-induced muscle damage and potential mechanisms for the repeated bout effect. Sports Med 1999;27:157-70.

3 McHugh MP, Connolly DAJ, Eston RG, et al. The role of passive muscle stiffness in symptoms of exercise-induced muscle damage. Am $\mathcal{F}$ Sports Med 1999;27:in press

4 Gleim GW, McHugh MP. Flexibility and the effects on performance and sports injuries. Sports Med 1997;24:289-99.

5 Nosaka K, Clarkson PM. Influence of previous concentric exercise on eccentric exercise-induced muscle damage. F Sports Sci 1997;15:477-83.

6 Brown SJ, Child RB, Day SH, et al. Exercise-induced skeletal muscle damage and adaptation following repeated bouts of eccentric muscle contractions. F Sports Sci 1997;15:215-22. 